\title{
Plato's Response to the Third Man Argument in the Paradoxical Exercise of the Parmenides
}

\author{
Bryan Frances \\ Penultimate version; final version published in \\ Published in Ancient Philosophy v. 16 (1996), 47-64
}

For all these reasons, then, the One is and becomes older and younger than itself and the others, and neither is nor becomes older or younger than itself or the others (155d).

The long second part of the Parmenides includes many fantastic, apparently contradiction-ridden statements similar to the one above. The problem of formulating a convincing interpretation of the dialogue that makes sense of these statements has proven so difficult that it has simply been ignored by most commentators on the third man argument (or arguments) found in the first part of the dialogue. This by itself may be a serious defect of these analyses of the third man argument given by these scholars. For Plato made it clear (135d) that he thought the truth regarding the problems of the first part of the dialogue-such as that of the third man-is to be found by undertaking the intellectual 'exercise' demonstrated by Parmenides in the second part of the dialogue. And it is also clear that after writing the Parmenides Plato continued to endorse a theory of Forms. Thus, he must have thought that the problems brought up in the first part of the dialogue were to be treated utilizing the considerations from the second - treated in such a way that the problems do not rule out a theory of Forms continuous with that presented in the earlier dialogues. Therefore, in order to see how Plato formulated and countered these problems one must do the dirty work; one cannot rest content, as most have done, with some interpretation that fails to locate Plato's response to the third man argument firmly in the second part of the Parmenides. One must, under pain of misinterpretation and irrelevance, explain the significance that the paradoxical arguments of the second part have for the problems of the first part.

I suspect that we have all known this is true. In spite of that uncomfortable knowledge, reams have been written on the first quarter of the dialogue, while the last three quarters are usually completely ignored, as if to say that Plato was not really serious when he insisted that we exercise as Parmenides 
demonstrated in order to see our way through the difficulties such as that of the third man. This is not to say that no good work can be done while ignoring the opaque parts of the dialogue; Vlastos' catalytic 1954 paper was a watershed despite its neglect of the latter three quarters of the dialogue. But it does imply, despite many scholars' hopes, that in the absence of a detailed understanding of the multitude of paradoxical arguments, any claim to know what Plato thought of the third man argument is simply without any foundation. Of course, the reason for the neglect of the last three quarters of the dialogue is obvious enough: interpreting the rest of the dialogue has looked utterly hopeless. Despite the best efforts of the ablest scholars, most of the arguments in the latter part of the dialogue have appeared to be incomprehensible.

Constance M einwald (1991) has offered a new and perhaps revolutionary interpretation of the dialogue that takes Plato at his word in interpreting his stance toward the problems raised in the first few pages of the dialogue. $-\mathrm{M}$ einwald claims it is probable that all the apparent contradictions in the Parmenidean dialectic are just that, merely apparent. Furthermore, both in that book and in 'Goodbye to the Third Man' (1992) she offers a new solution to the problem of the third man as one of the centerpieces of her interpretation of the dialogue. She also claims that Plato implicitly endorsed it. Commentators have found this solution compelling. Kenneth Sayre, for example, considers her solution 'a major contribution to the literature on [the] topic [of the third man]' $(1994,115)$. J.D.G. Evans conjectures that M einwald's solution 'may be formally successful in blocking the unwanted inferences' in the third man argument $(1992,334)$. P.K. Curd straightforwardly suggests that M einwald's solution is successful: 'most of the problems Parmenides poses for the theory of Forms can be resolved by attending to the distinction that [M einwald uncovers and] is at the heart of the dialectical exercise' $(1992,628)$.

While I share these commentators' enthusiasm for the originality, force, and plausibility of Meinwald's interpretation, I am not convinced she has either adequately solved or uncovered Plato's position on the problems raised by Parmenides in the first part of the dialogue. I shall focus on the most famous of these problems, that of the third man. I will show that if her interpretation of the Parmenides is accurate, then there are two kinds of Forms for which her solution to the third man problem fails, those that have species and those for which there hold a certain sort of true self-predications-in her scheme, pros ta alla self-predications. (On her interpretation the Forms Being, Rest, Eternality, and the One, for example, satisfy this latter condition.) However, even though M einwald's solution to the problem of the third man may be incomplete, this is most likely a minor defect in her project. Unlike most treatments of 
the third man argument, M einwald's main goal is to interpret the Parmenides-especially the second part and its relation to the first part-not solve the problem of the third man. $\underline{2}$

Independently of her difficulties with the third man argument, it appears that M einwald has proven that Plato had a plausible partial response to the third man argument implicit in the second part of the Parmenides. Thus, two possibilities should be kept in mind: (a) Meinwald's interpretation may be the first accurate and thorough exposition of the Parmenides but Plato's response in that dialogue to the third man argument may be flawed in ways unrecognized by Plato, or (b) Plato indicated some other way of dealing with these special flaws. I will offer reasons to think that option (b) is the correct one. I will argue that if M einwald's interpretation is accurate, then right in the Parmenides Plato solved the problem of the third man in the manner suggested independently by some scholars in this century.

\section{Two Kinds of Predication}

I shall now present the central aspects of Meinwald's predication distinction and differentiate her distinction from similar ones. I will neither recite nor criticize her elaborate arguments that this distinction is the centerpiece of the second part of the Parmenides; such a project is the subject for another essay.

According to M einwald one kind of predication to be found in the Parmenides concerns the relations among the natures of Forms. True claims of the form ' $\mathrm{A}$ is $\mathrm{F}$ pros heauto (in relation to itself)' are 'grounded in relations between [the] natures' of the Forms A and the F $(1991,67)$. M einwald claims that 'asking whether $A$ is $F$ pros heauto is equivalent to asking whether [the] $F$ appears above [or at] A in A's [Platonic genus-species] tree' (1991, 69, cf. 71, 79, and 80). M einwald suggests other intuitive formulations of the claim that $\mathrm{A}$ is $\mathrm{F}$ pros heauto (cf. 1991, 66-67).

Being $F$ (or an $F$ ) is at least a part of being $A$ (or an $A$ ).

The nature of the $F$ is at least a part of the nature of $A$.

At least a part of what it is to be $A$ (or an $A$ ) is to be $F$ (or an $F$ ).

For example, in the case of the Form Color and some particular shade of red, call it 'Red', being a Color is part of being Red; the nature of Color is a part of the nature of Redness. Thus, the claim 'Redness is 
Colored pros heauto' is true in virtue of the relation between the natures of the two Forms. Another example of pros heauto predication concerns the relation between Justice and Virtue. According to Plato the Form Justice is a species of the Form Virtue: being virtuous is part of being just; so the nature of Virtue is part of the nature of Justice. According to M einwald, Plato (if he knew some English) would express this proposition with the sentence 'Justice is Virtuous pros heauto'. On M einwald's interpretation of Plato, the only objects with natures, the only objects for which one can give a definitional account, are Forms; thus, all true pros heauto claims will be about Forms, not individuals such as Socrates (cf. 1991, 71, 178n17).

According to M einwald it is not the case that all true pros heauto claims are true in virtue of a Form falling under another in a genus-species relationship. For instance, 'Red is Red pros heauto' is a trivially true pros heauto claim; it just says that the Form Redness appears at the very same place in the genusspecies tree that the Form Redness appears. More precisely, it is the claim that the nature of the Form Red is at least a part of the nature of the Form Red. All such self-predications are true pros heauto claims.

Pros heauto predications are meant to bring out what is true about a Form in virtue of its 'nature', what properties could be mentioned in a definitional account of just that thing, what is definitionally true of it, or, perhaps best, what Forms are at least a part of the nature of the subject. These phrasings are, I think, not as clear as one might want; their force can be ascertained only by studying how Plato makes pros heauto predications in the Parmenides. M einwald offers what appears to be an official analysis of pros heauto predications slightly different from the one suggested in the quotations above: 'if what it is to be an $A$ is to be a $B$ with certain differentia (or series of differentiae) added', then $B, A$, and any of the differentiae can be truly predicated pros heauto of $A(1992,379)$. The difference, if genuine, between this characterization and the one given above is captured by the addition of the clause regarding differentiae. If we fantasize that the Form Animal is the genus and Bipedal the differentia of Human, then both 'The Human is an Animal' and 'The Human is Bipedal' will be pros heauto truths. Thus, it is not quite correct that ${ }^{\top} \mathrm{A}$ is $\mathrm{F}$ pros heauto ${ }^{\top}$ is true if and only if the $\mathrm{F}$ appears above or at $\mathrm{A}$ in $\mathrm{A}$ 's Platonic genus-species tree. ${ }^{3}$ This schema leaves out differentiae if they do not appear in genus-species trees. Thus, pros heauto truths about a Form serve to locate it in its Platonic genus-species tree.

Some of the glosses for pros heauto predications do not seem to be true when $A$ and the $F$ are identical: e.g., Justice is J ust pros heauto but Justice does not get mentioned in any definitional account of Justice. 
One is tempted to cash out the 'definitional account' gloss with something like this: the $\mathrm{F}$ gets referred to by some proper part of a definiens of $A$. But that does not help much when $A$ is none other than the F; it makes self-predications that are read pros heauto into falsehoods, which is incorrect. For instance, if A is the Human and the definiens is 'the animal that is bipedal', then it would be odd to say that the Human was mentioned in the definiens (even though it may be the referent of the definiens). And it would be false to say that the Human was referred to by some proper part of any correct definiens. Since some of the natural glosses of pros heauto predication do not apply straightforwardly to selfpredications in such a way to give them true readings, it is best to keep in mind M einwald's official analysis excerpted in the previous paragraph. The only satisfactory and somewhat colloquial glosses I have found to cover every case are ' $\mathrm{r} A$ is $F$ pros heauto ${ }^{\prime}$ is true if and only if the nature of the $F$ is at least a part of the nature of $A$ ' and, what I will use, ' $\ulcorner A$ is $F$ pros heauto $\urcorner$ is true if and only if the $F$ is definitionally true of $A^{\prime}$. The latter gloss should be taken to allow for true self-predications.

It is tempting to train one's focus on Meinwald's use of the genus-species criterion or her references to the nature of Forms and then shelve her interpretation as a variant of someone else's (defective) theory. I doubt that one will have much success in this endeavor. For starters, one should not think that pros heauto predication is the same as either necessary predication, necessary predication restricted to Forms, or Aristotle's said-of-a-subject predication from the Categories. Various things can be truly saidof-Socrates (he is human) but nothing is true pros heauto of Socrates, on M einwald's view, since there is no definition of Socrates, no definitional account of what it is to be a Socrates, what being a Socrates is. The fact that Socrates is necessarily human is not to the point; neither is it relevant that we can express the fact with either 'part of the nature of Socrates is to be human' or 'part of what it is to be Socrates is to be human'. This is not the use of 'nature' M einwald employs; her use is strictly tied to objects with definitions. Since Socrates is not a Form he does not merit true pros heauto predications; it does not make sense (except in a metaphorical manner) to say what being a Socrates consists in. Thus, the straightforward Aristotelian analogy is flawed. Some necessary predications-involving individuals or Forms-are not pros heauto predications: it is necessary to the Form the Human that it be, be intelligible, be self-identical, and be at rest, but these do not hold of it in virtue of pros heauto predications since one would not, in giving an definitional account of what the Human is, mention either that it is, is intelligible, is self-identical, or is at rest. To give a definitional account of a Form is to single it out by mentioning its genus (or genera) and differentia (or series of differentiae). In giving a definitional account of the Human, one might mention that it is a species of the Animal with Bipedal as differentia; 
so the Animal and Bipedal will be true of the Human pros heauto. But the fact that the Human is or is one or is self-identical or is at rest-even necessarily so-does not help to single out the Human. So pros heauto predication does not encompass necessary predication-even if we restrict necessary predications to those involving Forms. Finally, the example involving Rest and the Human ('the Human is at Rest' is true but not a pros heauto truth) clearly demonstrates that M einwald's approach is not a variant on those that try to drive a wedge between predication of Forms and predication of individuals. Although pros heauto predications are true only of Forms, there are many diverse and important pros ta alla predications (to be discussed below) true of Forms. For example, the Forms Rest and Being are, on Meinwald's interpretation, truly predicated pros ta alla of both Justice and, say, Cyprus; clearly these are not pros heauto truths since Justice is not at rest by definition and Cyprus is not a Form. So pros ta alla predication cannot be interpreted to stand for predication of individuals (non-Forms) alone.

Some Forms call for special comment. The Form Being might be thought to be true of every Form pros heauto. After all, Being is part of being human, or being just or being $F$, for any Form the $F$. Thus, part of what it is to be $\mathrm{F}$ is to be; this is similar to glosses such as 'part of what it is to be human is to be an animal'. So Being appears in the definitional account of every Form. Thus, rthe $F$ is pros heauto $\urcorner$ should be true for every Form. The argument is correct up to but not including the two conclusions. Being will not get mentioned in singling out or giving an analysis or definitional account of Justice; so Being is not definitionally true of Justice. The same holds for any Form that applies to every Form, e.g., The One, Self-Identical, Changeless, Rest, Eternality. Although part of what it is to be $F$, for any Form $F$, is to be One (thing), the One does not appear in the required sense in the definition of $F$ : you would hardly mention that Justice is one thing in pointing out its place in its genus-species tree. In the definition 'the Human is the Animal that is Bipedal' Being is neither the subject nor predicated of the subject; therefore, it is not mentioned in the definition in the required sense.

The other form of predication to be found in the dialogue is indicated by the phrase 'pros ta alla' ('in relation to the others'). Negatively put, these are the non-pros heauto predications. Positively characterized, they are supposed to be what we consider perfectly ordinary predications. In asking whether $A$ is $F$ pros ta alla, we are asking whether A 'displays some feature that conforms to the nature' of the Form the F (cf. 1991, 62-63). For example, if Socrates is just, then he must display some feature that conforms to the nature of the Form Justice. If being just is having a soul in psychic harmony, then Socrates must have such a soul in order for 'Socrates is Just pros ta alla' to be true. Unlike true pros 
heauto claims, true pros ta alla claims can be about either individuals or Forms, i.e., in the truth $\mathrm{rA}$ is $\mathrm{F}$ pros ta alla $\urcorner$ A may be either an individual or a Form. For instance, both Socrates and Justice are One pros ta alla because both display features that conform to the nature of the One or Oneness; both satisfy the conditions for being one thing. Meinwald intends that we do not read 'feature', 'display', or 'conform' as referring to technical notions harboring some preconceived set of assumptions. Indeed, I believe that M einwald's use of these terms is merely suggestive; they do not apply very well to some cases of pros ta alla predication. For example, both 'Socrates is pros ta alla' and 'Socrates is one pros ta alla' are true, but it is awkward to say that he displays some features that conform to Being and the One (what would the features be? what is the force of 'displays' here?). If one wants to force this gloss employing these terms, then one should not, as I think M einwald does not, take the occurrences of 'feature' and 'display' too seriously. What is important about true pros ta alla claims about Socrates is that 'whether or not Socrates' features are peculiar to him, his display of them will be a particular display, which is distinct from and may well be different from the displays made by other individuals' $(1991,61)$. If we wish to take displays in an ontologically serious manner, then they would be something like individual or internal parts of individuals, e.g., Socrates' soul is his display of a harmonious soul that conforms to the nature of the Form Justice. Meinwald does not indicate whether or not we are always to take these references to displays in this manner.

The fact that the phrase 'pros ta alla' gets translated as 'in relation to the others' can easily lead to a confusion. It is natural to take the occurrence of 'the others' to signify something other than the subject of the sentence. Thus, sentences of the form 'the $F$ is $F$ pros ta alla' do not appear to be even wellformed since they would be saying that the $F$ is $F$ in relation to something other than $F$. But this is nonsense; for what could the 'other' be here? All we have is the Form the F. Thus, pros ta alla predications must mention at least two things, a subject and a Form distinct from and predicated of the subject. This objection fails for the simple reason that in the Parmenides Plato claims that the One is One in a pros ta alla section (145a, cf. 155e). He could not make such a claim if this objection were sound. Furthermore, we do want to say things like every Form is, is eternal, is at rest, and is intelligible pros ta alla. All Forms are at rest pros ta alla since each conforms to the nature of the Form Rest; to say that a Form is at rest is a perfectly ordinary (pros ta alla) predication. Thus, since Rest is a Form it too is at rest pros ta alla, i.e., Rest is at rest pros ta alla. This is a perfectly straightforward pros ta alla truth even though there is no mention of some other. The moral is that one should not take the occurrence of 'the others' in the translation too literally. ${ }^{4}$ An analogous point holds for pros heauto predications. Just 
because 'pros heauto' gets translated as 'in relation to itself' does not mean that the only well-formed predications of this type must be self-predications. That is, the translation does not entail that ' $\mathrm{A}$ is $\mathrm{F}$ pros heauto' is well-formed if and only if $A$ is identical to the $F$. Instead, the bit about 'itself' means that we are talking about the nature of the Form A itself, not its 'displays of features', which are less 'internal' to the Form. Remember: natures are determined by the Forms mentioned in definitions, not the Forms mentioned in any old necessary truths.

Applying the predication distinction to the arguments in the second part of the Parmenides in order to dissolve all the apparent contradictions is not at all trivial, and I will not take it up here. (M einwald uses the bulk of her book in order to show how to carry out this important project for several special cases.) However, it is relatively simple and instructive to see how it works in some cases. For example, in the first two sections of the dialectic Plato says that if the One is, then it both does and does not have parts $(142,137)$. These two apparently contradictory consequents are seen to be consistent once we distinguish the two types of predication. According to Meinwald Plato is rightly claiming that (if the One is, then) the One neither is identical to nor is a species of the Form Parthood, i.e., the One does not have parts pros heauto. But Plato is also right in claiming that (if the One is, then) the One does have parts pros ta alla; since the Forms Being and Rest can be truly predicated pros ta alla of the One, for instance, the One has a structure partially composed of its pros ta alla displays of Being and Rest. According to Meinwald these displays count as parts. Thus, the One displays some feature (its complex of parts [displays]) that conforms to the nature of the Form Parthood, i.e., it counts as having parts. Thus, the two consequents are not contradictory. Independently of the difficulties in applying the predication distinction to all the apparently contradictory passages, it seems clear that with its aid it has become possible to bring some order to the most problematic passages in the dialogue-a truly remarkable achievement. ${ }^{5}$

\section{Meinwald's Solution to the Third Man Argument}

M einwald claims that the problems for the theory of Forms raised in the first section of the dialogue are solved by distinguishing the two forms of predication. The most famous of these problems is that of the third man. Parmenides' third man argument (131e9-132b3) can be filled out as follows:

1. $a$ and $b$ are $F$. 
2. If there is a plurality $P$ each of which is $X$, then there is exactly one Form that (a) is distinct from each of $P,(b)$ is such that each of $P$ is $X$ in virtue of it, and (c) is $X$.

3. By (1) and (2) there is exactly one Form - call it Fness - that (a) is distinct from a and b, (b) is such that $a$ and $b$ are $F$ in virtue of it, and (c) is $F$.

4. By (1) and (3c) a, b, and Fness are F.

5. By (2) and (4) there is exactly one Form - call it Fness ${ }_{1}$ - that (a) is distinct from a, $b$, and Fness, (b) is such that $a, b$, and Fness are $F$ in virtue of it, and (c) is $F$.

\section{By (5a) Fness is not identical to Fness1.}

Of course there are many other plausible formulations of this argument, but the only steps that are crucial to my and M einwald's purposes must be akin to steps (2a) and (2c), the non-identity and selfpredication premises. These steps are uncontroversially a part of the third man argument (although their significance and exact formulation do not enjoy such status). So I will ignore the controversies regarding how, exactly, the argument is supposed to go (e.g., whether step (2) should posit a unique Form or just at least one Form). - By reiterating steps (3)-(6) infinitely we discover that each thing that is, for instance, white, is white in virtue of not just one but an infinite number of Forms. However, as was indicated in step (2b) Plato's claim seems to be that there is exactly one thing in virtue of which white things are white. Therefore, steps (3b), (5b), and (6), all of which are consequences of the principle in (2) (plus the factual claim of (1)), form an unsatisfiable set. Thus, the view based on the principle in (2) is inconsistent.

According to M einwald the problem lies in the self-predicative claim that Fness is F. M ontblanc and Venus may be large, but the Form the Large certainly is not large, at least not in the same way Montblanc and Venus are large. So either 'the Large is large' is obviously false and Plato has made a rather gross error, or the Form the Large is being predicated of the Large in a way different from the way it is predicated of M ontblanc and Venus. In support of this latter option M einwald's two forms of predication play the essential role. Recall that to say a is $\mathrm{F}$ pros heauto is to say that the $\mathrm{F}$ is at least part of the nature of $a$; the $F$ is definitionally true of a. M einwald thinks it is pretty clear that the Large is large pros heauto: it is true that Largeness is definitionally true of the Form the Large. ${ }^{?}$ On the other hand, to say that a is F pros ta alla is to say that a displays some feature that conforms to the nature of the F. Since M ontblanc, Venus, and other ordinary large objects are large pros ta alla but not large pros heauto, and the two kinds of predication are different, we conclude that largeness is being predicated of 
the Large in a way different from the way it is being predicated of M ontblanc and Venus. In light of these different forms of predication M einwald would formulate the true intuitions behind the third man argument as follows (cf. 1991, 155-157):

$1^{\prime}$. a and $b$ are $F$ pros ta alla.

2 '. If there is a plurality $P$ each of which is X pros ta alla, then there is exactly one Form that (a) is distinct from each of $P,(b)$ is such that each of $P$ is $X$ pros ta alla in virtue of it, and (c) is $X$ pros heauto.

$3^{\prime}$. By $\left(1^{\prime}\right)$ and $\left(2^{\prime}\right)$ we infer that there is exactly one Form - call it Fness-that (a) is distinct from a and $b$, (b) is such that $a$ and $b$ are $F$ pros ta alla in virtue of it, and (c) is $F$ pros heauto.

She claims that the proper formulations of the intuitions that drive the argument fail to lead to regress or inconsistency. As before, $\left(1^{\prime}\right)$ and $\left(3^{\prime} c\right)$ entail that there is a plurality $Q$ consisting of $a, b$, and Fness each of which is $\mathrm{F}$-but this time not all of the members of $\mathrm{Q}$ are $\mathrm{F}$ pros ta alla. In particular, Fness is not $\mathrm{F}$ pros ta alla - it is F pros heauto. For example, the Large is not large and Redness is not red pros ta alla; Forms are neither colored nor have size. So we cannot reuse $\left(2^{\prime}\right)$ for plurality $Q$ to derive the regress or inconsistency. What is essential to M einwald's solution to the third man argument is that (a) the members of plurality $P$, i.e., the participants of Fness, are $F$ in a way different from the way Fness is $F$, (b) the members of $\mathrm{P}$ all are $\mathrm{F}$ pros ta alla, and (c) the crucial claim ${ }^{\mathrm{F} F n e s s}$ is $\left.\mathrm{F}\right\urcorner$ is a pros heauto claim. Meinwald claims that this is the end of the problem of the third man: 'Plato's metaphysics can say goodbye to the Third Man' $(1991,157)$.

Surely M einwald is correct in saying that in order for 'The Large is large' to present any problems it must be the same kind of claim as 'M ontblanc is large', i.e., a pros ta alla claim. It is clear that the Large is large pros heauto and is not large pros ta alla. And since, on M einwald's view, claims of the form 'the F is F pros heauto' are truisms, it is equally obvious that the Large is large pros heauto. The same holds for the Forms Justice, the Cat, etc. M einwald's solution appears to succeed in that it seems to block the third man argument for some forms, and it is reasonable to hold that it was the solution Plato was indicating in the Parmenides, for the following reason. Consider first that it appears that part of Plato's objective in the long second part of the dialogue was to introduce and illustrate the pros ta alla/pros heauto predication distinction. Furthermore, according to Plato this part of the dialogue was supposed to provide the intellectual exercise necessary in order for one to avoid the traps-such as that of the 
third man - that Parmenides revealed in the first part of the dialogue and that are associated with an immature theory of Forms and participation. Thus, it is reasonable to conclude that the predication distinction is both the central element of the exercise and the heart of the solution of the third man problem. By arguing that Plato had this predication distinction in mind for this purpose Meinwald has certainly offered an appealing answer to the age-old question of how Plato thought the problem of the third man was to be solved by the paradoxical dialectic.

\section{The Inadequacy of M einwald's Solution}

If a solution to the problem of the third man is to be complete, then it must eliminate the inconsistency for the Forms the $\mathrm{F}$ for which there is a set of things (other than the $\mathrm{F}$ ) that participate in the $\mathrm{F}$ pros ta alla, and the claim rthe $F$ is $F$ pros ta alla $\urcorner$ is true. If both of these conditions hold then the third man argument can be applied to the $\mathrm{F}$ to reach inconsistency. M einwald's solution fails in these cases. The inconsistency arises for the Forms Being and the One, for example, since according to M einwald's interpretation the One is one pros ta alla and Being is pros ta alla, i.e., the One satisfies the conditions for being one thing (96), and there is such a Form as Being. According to M einwald's account of the two forms of predication, the Form Being is predicated of both Socrates and the Form Justice in the same way that it is predicated of itself: each of the three displays some feature that conforms to the nature of Being; each satisfies the conditions for conforming to the nature of the Form Being; each has Being pros ta alla. Thus, there is a set consisting of Socrates, Justice, and Being all of which are pros ta alla. So, by step ( $2^{\prime}$ a) in Meinwald's formulation of the third man argument there is a Form-Being ${ }_{1}$-which is distinct from Socrates, Justice, and Being. Thus, we have started the infinite regress of Forms of Being. The same problem evidently arises for the Forms the One, Rest, Intelligibility, and Eternality: for example, Eternality (as well as the Forms Parthood, Justice, etc.) is Eternal pros ta alla. ${ }^{9}$ In fact, the inconsistency is present for any Form the $\mathrm{F}$ for which there is a set of things (other than the F) that participate in the $\mathrm{F}$ pros ta alla, and the claim rthe $\mathrm{F}$ is $\mathrm{F}$ pros ta allar is true. 10

This is not to say that these problematic Forms cannot be truly predicated of themselves pros heauto. That is, in saying that 'Being is' has a true pros ta alla reading, I am not saying that the form Being cannot be truly predicated pros heauto of itself. The sentence 'Being is' is ambiguous (like every other predication that does not indicate what type it is of); it can mean either (i) the Form Being, like every other thing that is, displays some feature that conforms to the nature of the Form Being, or (ii) the Form 
Being is at least part of the nature of, is definitionally true of, the Form Being. My point in the previous paragraph is that reading (i) is true on, and the source of a third man problem for, M einwald's interpretation. This is not to say that reading (ii) is false or a piece of nonsense.

But that is not all. So far we have seen that M einwald's proposed solution to the third man argument fails for all those Forms that have true pros ta alla self-predications (e.g., the One, Being, Rest, and Eternality). In addition, if her interpretation of the response to the third man argument is accurate, then the third man argument goes through for any trio the $F_{1}$, the $F_{2}$, and the $F_{3}$ such that $r$ the $F_{1}$ is $\left.F_{3}\right\urcorner$, rthe $F_{2}$ is $\left.F_{3}\right\urcorner$, and rthe $F_{3}$ is $\left.F_{3}\right\urcorner$ are pros heauto truths.

To see this, recall M einwald's claim that the legitimate intuitions behind the third man argument generate only $\left(2^{\prime}\right)$, which was not supposed to lead to any regress or inconsistency.

$2^{\prime}$. If there is a plurality $P$ each of which is X pros ta alla, then there is exactly one Form that $(a)$ is distinct from each of $P,(b)$ is such that each of $P$ is $X$ pros ta alla in virtue of it, and (c) is $X$ pros heauto.

It seems to me that M einwald may not have fully specified the Platonic intuitions that generate the third man argument. I suspect that under her interpretation the intuitions generating the third man argument regard only particulars having something in common, e.g., being large. Sure enough, the example involving Largeness and large particulars is Plato's illustrative choice in the Parmenides. But the intuitions behind the third man argument may come from considering pros heauto commonalities among Forms as well as non-Forms. For example, in the M eno (72c) Plato looks to the many virtues (e.g., Courage and Justice) to posit what they have in common, 'some common character' that makes them virtues; this will end up to be Virtue itself, which is distinct from the individual virtues. And Plato's self-predications regarding Holiness, Equality, Largeness, Beauty, and J ustice ${ }^{11}$ give credence to the belief that Plato would accept the claim 'Virtue is virtuous'. These obvious points regarding Plato's beliefs seem to force us to conclude that he would accept intuitions sufficient for all three parts of the crucial premise of the third man argument, where the Form X is Virtue and the plurality P consists of the virtues: 
2. If there is a plurality $P$ each of which is $X$, then there is exactly one Form that (a) is distinct from each of $P,(b)$ is such that each of $P$ is $X$ in virtue of it, and $(c)$ is $X$.

That is, intuitions regarding the virtues and the Form Virtue are sufficient to generate the key premise in the third man argument. Thus, it appears that Plato may have supported the third man argument with intuitions regarding Forms participating pros heauto in Forms, and not merely particulars participating pros ta alla in Forms. If this is right and Plato did not forget about these cases, then M einwald's treatment of the third man argument cannot be all of Plato's response to that argument. In order to offer a complete response to the third man argument Plato would have to treat the cases in which each element of the plurality is a Form which is X pros heauto. Although M einwald seems to have overlooked these cases, I do not see how Plato could have.

If this is right, and M einwald is correct in thinking that the predication distinction was Plato's response to the problems Parmenides raised in the first part of the dialogue, then Plato would have been led to try to apply his newfound predication distinction to these pros heauto cases, i.e., cases involving a trio the $F_{1}$, the $F_{2}$, and the $F_{3}$ such that rthe $F_{1}$ is $\left.F_{3}\right\urcorner$, rthe $F_{2}$ is $\left.F_{3}\right\urcorner$, and $\left\ulcorner\right.$ the $F_{3}$ is $\left.F_{3}\right\urcorner$ are pros heauto truths. Assuming Plato applied M einwald's approach (embodied in $\left(2^{\prime}\right)$ ) to the pros ta alla cases of the third man problem, we can conjecture that when reflecting on the pros heauto cases, he might have been led, in exact parallel with M einwald's ( $2^{\prime}$ ), to propose the following as a formulation of the true intuitions behind the pros heauto cases:

2 ". If there is a plurality P (e.g., Courage and Justice) each of which is X (virtuous) pros heauto, then there is exactly one Form (Virtue) that (a) is distinct from each of $P,(b)$ is such that each of $P$ is $X$ (virtuous) pros heauto in virtue of it, and (c) is X (virtuous) pros heauto.

Whereas ( $\left.2^{\prime}\right)$ is geared towards solving the third man problem generated by pros ta alla predications, $\left(2^{\prime \prime}\right)$ is geared toward solving the third man problem generated by pros heauto predications. The problem starts when we realize that $\left(2^{\prime \prime}\right)$ is true on M einwald's interpretation. Specifically, the antecedent is true because the Forms Courage, Justice, and Piety all are Virtuous pros heauto. They all are Virtuous pros heauto because each satisfies the conditions set out in one of the glosses for true pros heauto claims given earlier: Virtue is at least a part of the nature of each Form. M ore importantly, we 
can reuse $\left(2^{\prime \prime}\right)$ for plurality $Q$, which includes plurality $P$ as well as Virtue itself. And that will generate Virtue $_{1}$ and the resulting inconsistency. To summarize:

$1^{\prime \prime}$. Justice and Courage are Virtuous pros heauto.

2 ". If there is a plurality P each of which is X pros heauto, then there is exactly one Form that (a) is distinct from each of $P,(b)$ is such that each of $P$ is $X$ pros heauto in virtue of it, and (c) is X pros heauto.

$3^{\prime \prime}$. By $\left(1^{\prime \prime}\right)$ and $\left(2^{\prime \prime}\right)$ there is exactly one Form - call it Virtue-that (a) is distinct from Justice and Courage, (b) is such that Justice and Courage are Virtuous pros heauto in virtue of it, and (c) is Virtuous pros heauto.

$4 "$. By $\left(1{ }^{\prime \prime}\right)$ and $\left(3^{\prime \prime} c\right)$ Justice, Courage, and Virtue are Virtuous pros heauto.

$5^{\prime \prime}$. By $\left(2^{\prime \prime}\right)$ and $\left(4^{\prime \prime}\right)$ there is exactly one Form - call it Virtue ${ }_{1}$-that (a) is distinct from Justice, Courage, and Virtue, (b) is such that Justice, Courage, and Virtue are Virtuous pros heauto in virtue of it, and (c) is Virtuous pros heauto.

6 ". By (5"a) we infer that Virtue is not identical to Virtue.

By reiterating steps $\left(3^{\prime \prime}\right)-\left(6^{\prime \prime}\right)$ infinitely we discover that each thing that is Virtuous pros heauto is so in virtue of an infinite number of Forms - not just in virtue of a single Form Virtue. Steps ( 3 'b), $(5$ 'b), and $\left(6^{\prime \prime}\right)$ form an inconsistent set. The inconsistency comes from ( $\left.2^{\prime \prime}\right)$.

Of course, there is nothing special about the Form Virtue in this respect; the third man inconsistency is there for any Form the $F$ for which there are at least two non-self-predicative pros heauto truths of the form ' $\mathrm{A}$ is $\mathrm{F}$ '. Therefore, on her own interpretation M einwald has failed to avoid the third man inconsistency for these pros heauto cases. In sum: the third man argument is generated by Plato's own cases like the one involving virtues; M einwald's treatment of the third man argument ignores these cases; Plato probably would not have ignored these cases; and the most obvious way to alter Meinwald's treatment to deal with these cases makes Plato's response to the third man argument unsatisfactory by his own lights. Thus, I think that if Plato accepted M einwald's predication distinction and thought that it was the key to solving the problems raised by Parmenides, then he must have had either an additional facet to his treatment of the third man argument or some quite different approach. If I am wrong, and M einwald has accurately set out Plato's entire response to the problem of the third 
man, then he did not adequately treat the problem, for either the odd pros ta alla cases or the pros heauto cases.

In sum, M einwald's solution fails for any Form that satisfies what I will call 'the third man condition': the Form the F is $\mathrm{F}$ in the same way-pros ta alla or pros heauto-as some of its other participants are $\mathrm{F}$. One may wonder how important my counterexamples are to Meinwald's overall position on the third man argument. Could she just change her position in order to bypass them? I do not see how; the counterexamples cut pretty deep. Consider the pros ta alla counterexamples. The problematic selfpredications such as 'Eternality is Eternal', under one reading, seem straightforwardly to fit the scheme for pros ta alla predications and obviously fail to fit the scheme for pros heauto predications. That is, the problematic self-predications have a clear reading that for all the world looks like a pros ta alla predication that is true in Plato's metaphysics. (This is not to say they fail to have a reading that makes them pros heauto truths.) Given M einwald's notion of pros ta alla predication, 'Justice is at Rest' is a straightforward pros ta alla truth (even though it has an absurdly false pros heauto reading as well). In fact, given this intuition about Justice (i.e., 'Justice is at Rest pros ta alla' is true), there is no reason not to offer the generalization: every Form is at Rest pros ta alla. But since Rest itself is a Form, we can instantiate the generalization just given to get the problematic pros ta alla self-predication 'Rest is at Rest'. Cases like this count against the move, if one is tempted to make it, to think that the problems arise when we consider only really fundamental (and bizarre) Forms like the One and Being. On the contrary, take any property true of every Form and you have the problem.

This shows, I believe, that there is no obvious way to do away with the importance of these pros ta alla counterexamples to M einwald's solution to the third man argument. The pros heauto counterexamples appear well motivated as well.

\section{An Alternative Interpretation of Plato's Response to the Third Man Argument}

Assuming the accuracy of M einwald's interpretation-with the exception of her construal of Plato's view of the third man argument-what should Plato have said with respect to the argument? A common response in this century has been to reject, sometimes with verbal violence, self-predication, but this avenue is no longer reasonable for either set of counterexamples to M einwald's solution, the pros heauto and odd pros ta alla self-predications. For each counterexample involves a true self-predication: 
either 'the One is one pros ta alla' or 'Virtue is Virtuous pros heauto'. And we have seen that M einwald's solution is not quite adequate. However, that does not leave us empty handed. If M einwald's interpretation of the predication distinction is accurate, then there is another possibility that would have been open to Plato: drop what has been called 'the non-self-explanation assumption' and 'the nonidentity premise' (2a) (captured by (2'a) and (2“a)) which asserts that a Form must be distinct from all the things of which it can be truly predicated. More precisely, restrict ( $\left.2^{\prime} a\right)$ and (2"a) to apply to pluralities not including the $X$. This dissolves the problem of the third man in one stroke. If we are good Platonists who have Meinwald's predication distinction in mind, then we should be led to claim that (2a) must hold only for the participants other than the Form itself; the Form the $F$ (but nothing else) may indeed be $\mathrm{F}$-pros ta alla or pros heauto-in virtue of itself and not some other Form. The argument that Plato would have dropped (2a) (i.e., premises ( 2 'a) and ( $2^{\prime \prime}$ a)) comes in two parts, corresponding to the two types of predication.

First, Plato would be perfectly willing to admit that when there is a plurality Q - which does not contain the Form the $X$ - each of which is X pros heauto there must be a Form the $X$ distinct from each of $Q$, but when we admit that the $\mathrm{X}$ is X pros heauto, we have no inclination whatsoever to think we need another Form distinct from the $X$. Justice is J ust pros heauto in virtue of itself-for what other Form would be relevant? If J ustice is J ust because the nature of the Form Justice is at least a part-in fact the whole-of the nature of Justice, and it makes sense to ask 'In virtue of what Form is Justice Just?', then the only reasonable answer on M einwald's interpretation is 'Justice'. So there is no reason to insist on the generalization ' $(y)(X)(y \text { is } X \text { pros heauto } \rightarrow y \neq \text { the } X)^{\prime}$ ', i.e., on (2"a). Thus, if Plato really had Meinwald's predication distinction in mind, then he would have renounced ( 2 "a) when the plurality includes the Form the $X . \underline{12}$

Second, once one has understood pros ta alla predication there is no reason to accept the move from 'Being is, the One is one, Rest is at rest, and Eternality is eternal pros ta alla' to 'Being must be in virtue of something other than Being' and the corresponding statements for the other Forms. The One must be one pros ta alla in virtue of itself; for what other Form would be relevant here? If the One is one because it displays some feature that corresponds to its own nature, and it makes sense to ask 'In virtue of what Form is the One one?', the only reasonable answer on M einwald's interpretation is 'the One'. After all, although it may seem clear that the Forms Justice and Color are One pros ta alla in virtue of 'having' or being related to a common element which is not identical with either, it is hardly plausible 
that the One is not One pros ta alla in virtue of itself. Therefore, Plato would reject the generalization ' $(y)(X)(y \text { is } X \text { pros ta alla } \rightarrow y \neq \text { the } X)^{\prime}$, i.e., ( $\left.2^{\prime} a\right)$. That is, he would reject ( $\left.2^{\prime} a\right)$ when the plurality includes the X. Therefore, Plato would reject both ( $\left.2^{\prime} a\right)$ and ( $\left.2^{\prime \prime} a\right)$ when the plurality includes the Form the X; this amounts to a rejection of the non-identity premise $(2 \mathrm{a})$.

If this is right, then Being is in virtue of itself and Justice is J ust in virtue of itself-contrary to (2a). This option seems virtually required for those who accept Forms and M einwald's predication distinction. For our Platonic intuitions-matured upon discovering the predication distinction-support only the weaker claim that if each of a plurality $P$ not including the $X$ is $X$, then there must be some Form that is distinct from each of $P$ and is such that each of $P$ is $X$ in virtue of it. The stronger claim adds on a highly abstract part-the Form the $X$ cannot be $X$ in virtue of itself-that our M einwald-inspired intuitions not only fail to support but oppose. Once one has the predication distinction and the self-predications in mind, there is both reason to reject and no reason to accept (2a). Thus, it looks as though on the condition that Meinwald's interpretation is accurate, Plato would have done what some philosophers have recommended for years, pass on (2a). That is, if M einwald's interpretation is correct, then Plato solved the third man argument in the Parmenides in exactly the way recommended by some twentieth century scholars (e.g., Fine 1993)!

I am not sure what to think of this heady line of reasoning. It is reasonable enough to think that once one understands the nature of the two types of predication, one would not fall for either ( $\left.2^{\prime} \mathrm{a}\right)$ or (2 'a) when the plurality includes the Form the $X$. But did Plato grasp this point? In order to defend a positive answer, one must find evidence that Plato explicitly put all this together in the manner I have above. That is, one must assume M einwald's interpretation is essentially accurate and then show that Plato somewhere came to consider the peculiar natures of, on the one hand, pros ta alla truths such as 'Being is', 'the One is one', and 'Rest is at rest', and, on the other hand, pros heauto predications such as 'both the Animal and the Mammal are Mammalian' or, perhaps better, 'Justice, Charity, and Virtue are Virtuous'. The fact that M einwald did not put these considerations together in her ground breaking work proves that the leap is not obvious (for those working in English anyway).

Before one jumps to conclude that Plato must, at some point during or after composing the Parmenides, have realized that on this new theory of predication there was plenty of reason to reject both ( $\left.2^{\prime} \mathrm{a}\right)$ and $(2$ 'a), one should note that there are at least three reasons for doubting that this solution was the one 
to be obtained by exercising. First, since the dialectical exercise was supposed to help clear up the problems in the first part of the dialogue, including that of the third man, one would expect Plato eventually to make some reference to this mistaken premise-most likely in the Parmenides. Since he does not, it is at least doubtful that this is the response to the argument to be found by exercising, regardless of its merit.

Second, if this was the way out and he just never bothered to make it explicit, then why is it that none of his better students, Aristotle for instance, at least mentioned it? Third, Plato seems to imply (135d) that in order to avoid the problems associated with an immature theory of Forms and participation one needs to repeat the dialectic for many Forms, not just go through the exercise for the Form the One as Parmenides does. If we were to avoid the problem of the third man by dropping premise (2a), then why would he give such advice? Once we drop the premise the problem is solved for every Form; so there would be no reason to repeat the exercise.

Fortunately, there may be ways around the first and third criticisms. With respect to the first, one should not take it too far: it applies to just about any theory (including M einwald's) of what the response to the third man argument is supposed to be in the Parmenides. Since Plato nowhere explicitly indicates any considered view on the matter, his or anyone else's, it is difficult to marshal exegetical evidence for any involved response to the argument. That is partly responsible for the fact that until now we have had little idea what response to the problems pointed out by Parmenides was supposed to be obtained upon exercising as instructed. This observation does not refute the objection, but it lessens its force.

Not only can the third objection be defused, but its rebuttal prompts another argument in favor of my conjecture that Plato solved the problem of the third man by renouncing (2a). First, the objection is not conclusive since dropping premise (2a) may not be sufficient to solve all the problems considered in the first part of the dialogue. Second, as M einwald reminds us Plato's instance of the exercise with the One (as well as his discussions in other dialogues such as the Sophist) strongly suggests that there is a canonical list of predicates, 'a standard list of predicates whose holding or not holding must be checked out in each section' $(1991,119)$ of the exercise each time we go through it for some Form. The list of predicates is as follows. 
is many; has parts or is a whole; has beginning, middle, end; is limited; has shape (share of straight, curved); is anywhere (in itself or another); is in motion (alters, moves in place, changes place), is at rest; is same as or different from itself or another; is like or unlike itself or another; is equal or unequal to itself or another; is older than, younger than, same age as itself or another; is in time; was, has become, was becoming, will be, will become, is, becomes; is one; is the subject or possessor of anything, including name and logos, knowledge, perception, opinion (1991, 119-120).

Corresponding to this list of predicates is a list of Forms, the One, Being, Rest, Becoming, etc. Not only does the canonical list suggest what Forms we need to check against the Form of the hypotheses of the exercise (e.g., in the Parmenides, the One), but it suggests what Forms we are to exercise for. That is, we are to go through the exercise for each Form in the list, the One, Being, Rest, the Same, Eternality, etc. In carrying out this project, it is reasonable to think that one will eventually come across most of the true pros ta alla self-predications I marshalled as counterexamples against M einwald's proposed solution to the problem of the third man. Surely one will have hit enough of them to discover the pros ta alla half of the third man condition given earlier, viz. the Form the $F$ is $F$ in the same way-pros ta alla or pros heauto-as some of its other participants are $F$. And one would then be led to consider, by reflecting on self-predication in general, the third man condition as it applies to pros heauto predications as well. The conclusion is that one of Plato's reasons for repeating the exercise might have been to discover and analyze the peculiar self-predications, and in the light of the new predication distinction, drop the premise on which the third man argument rests.

None of this, of course, is conclusive. For all I have argued, Meinwald's faulty response to the third man argument is the one Plato held and my conjecture is completely mistaken. Nevertheless, I have shown that there is good reason to think that Plato went further than M einwald did and ended up giving, if not endorsing, a contemporary solution to the third man problem.

\section{Summary}

In this article I am not seriously challenging the accuracy of the main parts of M einwald's interpretation of the dialogue. Rather I am challenging her specific claim that with the distinction between the two forms of predication she (and Plato) can solve the problem of the third man in the manner presented in M einwald 1991 and 1992. Her proposal suffers from at least two defects: her solution fails for the 
problematic pros ta alla claims as well as in the pros heauto cases. In light of these problems we should not yet say 'good-bye to the Third Man'. There is, however, ample reason to think that if M einwald's exposition is accurate, then Plato did solve the problem of the third man in the Parmenides-in fact, in the very way suggested by some contemporary scholars. $\underline{13}$

\section{Bibliography}

Curd, P.K. 1992. rev. M einwald 1991. Review of M etaphysics 65: 627-628.

Evans, J.D.G. 1992. 'Predication and the Parmenides' Classical Review 42: 332-334.

Fine, Gail. 1993. On Ideas. Oxford: Clarendon Press.

Meinwald, Constance. 1991. Plato's Parmenides. New York: Oxford University Press.

Meinwald, Constance. 1992. 'Goodbye to the Third Man' 365-396 in The Cambridge Companion to Plato. Richard Kraut ed. Cambridge: Cambridge University Press.

Peterson, S. unpublished. 'Plato's Parmenides: A Principle of Interpretation and Seven Arguments'. Sayre, Kenneth. 1994. rev. M einwald 1991. Noûs 28: 114-116.

Vlastos, Gregory. 1954. 'The Third Man Argument in the Parmenides' Philosophical Review 63: 319-349. Vlastos, Gregory. 1981. Platonic Studies. Princeton: Princeton University Press.

\section{Notes}

1 Sayre 1994, Curd 1992, and Peterson (unpublished) agree that M einwald's efforts are among, if not superior to, the best in this century.

2M einwald's interpretation has the virtues of (i) being novel, (ii) locating in the second part of the dialogue a response to the objections of the first part, (iii) explaining why the second part has the structure it has (including the odd 'section' 155-157), (iv) providing the most plausible account of the relation of the two parts, (v) not having Plato arguing for a contradiction or changing the subject midway through the dialectic, and (vi) making reasonable the validity of the many dozens of arguments in the second part. I will not defend all these claims here. 
${ }^{3}$ Quotations using corner quotes - quasi-quotations - designate unspecified expressions, so 'A is $\mathrm{F}$ pros heauto' can be taken to indicate (but not refer to) the set of all expressions obtainable by substituting some names of Forms for the occurrences of ' $A$ ' and ' $F$ ', e.g., the expression 'Justice is Virtuous pros heauto'.

${ }^{4} \mathrm{Additional} \mathrm{reasons} \mathrm{against} \mathrm{this} \mathrm{move} \mathrm{are} \mathrm{given} \mathrm{below} \mathrm{in} \mathrm{note} 10$.

${ }^{5}$ The exercise of the Parmenides consists of eight sections, the first four of which have the hypothesis or antecedent, 'If the One is', the last four of which have the negation of this hypothesis. Oddly enough, Meinwald does not indicate the type of predication of these important predications. However, there are excellent reasons, which I will not elaborate here, for thinking they are pros ta alla predications.

${ }^{6}$ Commentators have given quite different formulations of the third man arguments (131e9-132b3 and 132d-133a3), disagreeing on (among other things) rules of inference, the scope of Forms subject to the argument, the existence and content of suppressed premises, and whether or not there is supposed to be a vicious non-explanatory regress or a logical inconsistency (or both). I am following M einwald in sidestepping such controversies; the reader can apply M einwald's predication distinction to his or her favorite formulation(s). I am also sidestepping the questions of whether Forms can exist uninstantiated and whether the plurality in step (1) could be singleton by assuming that it consists of at least two entities neither of which is any of the Fness's. That is, I assume that there are at least two entities a and $\mathrm{b}$ such that the true statements $\ulcorner\mathrm{a}$ is $\mathrm{F}\urcorner$ and $\mathrm{rb}$ is $\mathrm{F}\urcorner$ are not self-predications. I chose my formulation to be simple to follow and similar to the one that Vlastos 1981 settled on. Meinwald does not offer a formulation of the argument. She thinks, and I concur, that Plato's primary objective in these opening passages was to introduce quickly some intuitive problems with the immature theory of Forms he had adopted in the past. This accounts for the haste with which the arguments and responses are laid out.

7M einwald says that pros heauto self-predications are of 'a kind of identity statement' $(1991,106)$. I think this is misleading at best; self-predications are not identities in any sense since nothing is being identified with anything. One must be careful to distinguish, as I am certain M einwald does, 'Justice is Just' from 'Justice is J ustice'. The former is a self-predication-not an identity-with a true pros heauto reading. The latter is an identity-not a self-predication - short for 'Justice is identical to Justice' and is a straightforwardly true pros ta alla predication perhaps more conspicuously expressed by 'the pair 
\ustice, Justice>displays a feature that conforms to the nature of the Form Identity'. The same holds for identities involving individuals, e.g., 'Socrates is Socrates'.

8The idea of using a predication distinction to solve the third man problem is not new; however, a crucial part of M einwald's claim is that she has found in the second part of the Parmenides such a distinction being used to solve the problem of the third man, just as Plato indicated; most variants of this idea do not have this feature.

9M einwald claims that 'Justice is eternal' is a pros ta alla truth $(1991,101)$. This truth entails that the Form Justice displays some feature that conforms to the nature of the Form Eternality. But this holds for any Form; every Form is eternal pros ta alla. Thus, if Eternality is a Form, as M einwald claims, then like Justice (and every other Form) it is eternal pros ta alla, i.e., Eternality is Eternal pros ta alla.

10For reasons set out in the discussion of pros ta alla predication in section I, one cannot try to defuse this set of counterexamples by insisting that sentences of the form 'the F is F pros ta alla' are not even well-formed. There are further reasons for resisting this objection. Plato and M einwald need the wellformedness of claims of the form 'the $F$ is $F$ pros ta alla' in order to show that even though 'the Large is Large' has a true reading (pros heauto), its false reading (pros ta alla) is what is needed for the erroneous but natural intuitions behind the third man argument. M ore importantly, the selfpredications I have focused on are clearly true on Plato's metaphysics, fit the account of pros ta alla predication, and are not pros heauto predications. So they are well-formed. More on this below.

11See, for Justice and Holiness, Protagoras 330c-d; for Equality, Phaedo 75b; and for Beauty, Phaedo 100c, Hippias M ajor 292e, and Symposium 210e-211a.

12One might want to argue that Plato would be perfectly willing to give up (2"a) because he would admit that, e.g., Justice is just 'in relation to itself' (pros heauto), not something else. After all, that is precisely what 'Justice is just pros heauto' means. That is, 'Justice is just pros heauto' means Justice is just in relation to itself, not some other Form. So there is plenty of reason for thinking that Plato would insist that Justice could be Just pros heauto in virtue of itself, since that is what this type of predication amounts to. This argument is flawed for the reasons mentioned in section I and note 10. 
${ }^{13}$ An earlier version of part of this paper was presented at the M innesota Ancient Greek Philosophy Conference. Thanks to Sandra Peterson, M argaret Frances, and the editor for their valuable comments and suggestions. Special thanks to Sandra for her encouragement and hours of fruitful discussion. 